\title{
Role of radiotherapy in the treatment of primary mediastinal large B-cell lymphoma
}

\author{
JINGJING WANG, XIANLING LIU, FANG MA, MING HUANG, \\ YASHPAL SINGH KALLYCHURN and CHUNHONG HU
}

\begin{abstract}
Department of Oncology, The Second Xiangya Hospital of Central South University, Changsha, Hunan 410011, P.R. China
\end{abstract}
Received October 11, 2014; Accepted July 28, 2015

DOI: $10.3892 / \mathrm{ol} .2015 .3700$

\begin{abstract}
The role of radiotherapy (RT) in the treatment of primary mediastinal large B-cell lymphoma (PMLBCL) is unclear. In the present study, a retrospective analysis of 63 patients with PMLBCL treated with or without RT was performed to evaluate the role of RT. Clinical outcomes were calculated using the Kaplan-Meier method and were compared between patients who did and did not receive RT, using the log-rank test. A multivariate analysis was performed using Cox proportional hazards model. After chemotherapy, 35 patients received RT, and RT was found to be associated with significantly improved 5-year overall survival (OS) (87 vs. $58 \%$; $\mathrm{P}=0.001$ ) and 5 -year progression-free survival (PFS) (75 vs. $39 \%$; $\mathrm{P}=0.001)$ rates compared with patients without RT. The subgroup analysis on 35 patients who received rituximab plus chemotherapy showed that RT did not improve the 5-year OS ( 88 vs. $92 \% ; \mathrm{P}=0.814$ ) or the 5-year PFS (78 vs. $65 \%$; $\mathrm{P}=0.511$ ) rates compared with patients without RT. On multivariate analysis, RT and the addition of rituximab were predictive of increased OS [RT: Hazard ratio (HR), 0.157; $\mathrm{P}=0.018$; rituximab: $\mathrm{HR}, 0.156 ; \mathrm{P}=0.009]$ and PFS (RT: HR 0.111, $\mathrm{P}=0.001$; Rituximab: HR 0.231, $\mathrm{P}=0.002$ ) rates. However, the role of RT in PMLBCL in the rituximab era is unclear. Further investigation of the role of RT in the era of targeted therapy is required.
\end{abstract}

\section{Introduction}

Primary mediastinal large B-cell lymphoma (PMLBCL), which originates from thymic $\mathrm{B}$ cells, was once recognized as a distinctive clinical-pathological subtype of diffuse large B-cell lymphoma (DLBCL) according to the World Health Organization (WHO) in 2008 (1,2). PMLBCL affects young individuals,

Correspondence to: Professor Chunhong $\mathrm{Hu}$, Department of Oncology, The Second Xiangya Hospital of Central South University, 139 Renmin Road, Changsha, Hunan 410011, P.R. China E-mail: huchunh@medmail.com.cn

Key words: primary mediastinal large B-cell lymphoma, radiotherapy, rituximab, prognosis with a female prevalence. Patients present with a bulky mediastinal mass, which is commonly associated with adjacent organ infiltration and superior vena cava syndrome (3-5).

The optimal treatment for PMLBCL remains undefined. The cyclophosphamide, doxorubicin, vincristine and prednisone (CHOP) regimen is considered to be inferior to other more intensive regimens (6-10), such as the methotrexate, cytarabine, cyclophosphamide, vincristine, prednisone and bleomycin regimen (MACOP-B), dose-dense regimens, or even front-line consolidation high-dose therapy and autologous stem cell transplantation. However, none of these intensified approaches is now expected to provide results superior to those observed with rituximab plus CHOP (RCHOP). Rituximab, as a monoclonal antibody, has revolutionized the treatment of aggressive B-cell lymphomas $(11,12)$. A number of studies have confirmed that RCHOP improves the outcome of PMLBCL patients (13-15). Although the majority of patients initially respond to this therapeutic approach, certain patients relapse and eventually succumb to the disease. Therefore studies are currently focused on supplemental treatments such as radiation therapy (RT). The issue of whether the administration of RT after chemotherapy is beneficial to patients with PMLBCL remains unresolved, particularly in the rituximab era. Therefore, the present study summarized the clinical data of 63 PMLBCL patients, who were treated in affiliated hospitals (Xiangya hospital, The Second Xiangya Hospital and the Affiliated Cancer Hospital of Xiangya School of Medicine) of Central South University (Changsha, China) between January 2000 and January 2013, in an attempt to investigate the role of radiotherapy in PMLBCL.

\section{Patients and methods}

Patients. Patients with a histologically confirmed diagnosis of PMLBCL who were treated in the affiliated hospitals (Xiangya hospital, The Second Xiangya Hospital and the Affiliated Cancer Hospital of Xiangya School of Medicine) of Central South University between January 2000 and January 2013 were included in this analysis. The diagnosis of PMLBCL was based on the WHO criteria (2). All the patients were previously untreated and recruited without a history of previous malignant tumors, primary central nervous system involvement, severe coincident illnesses, second primary tumors or a positive human immunodeficiency virus status. 
Stage was defined according to the Ann Arbor staging system (16). The International Prognostic Index (IPI) was also evaluated (17). Bulky disease was defined as a mediastinal mass $>10 \mathrm{~cm}$ in diameter.

All patients included in the study completed 6-8 cycles of CHOP or CHOP-like chemotherapy with or without rituximab. All patients underwent imaging studies [positron emission tomography-computed tomography (PET/CT) or CT] to assess the response to chemotherapy (during and/or after completion of chemotherapy) (18). Treatment response was evaluated based on the International Working Group Recommendations for Response Criteria for Non-Hodgkin's Lymphoma, with complete remission (CR), partial remission (PR), stable disease (SD) and progressive disease (PD) statuses (19). At the completion of chemotherapy, involved field radiotherapy (IFRT) was allowed, at the treating physician's discretion. It was assumed that RT was more likely to be administered to patients with previously bulky disease, and disease that failed to achieve CR upon chemotherapy.

Statistical analysis. All statistical analyses were performed using SPSS software (version 13.0; SPSS, Inc., Chicago, IL, USA). The continuous characteristics, such as age, were presented as the median/range and were compared with the Wilcoxon rank-sum test. Other characteristics, including gender, Ann Arbor stage, lactate dehydrogenase level, bulky disease status, IPI score and chemotherapy regimen, were counted as categorical variables and compared by $\chi^{2}$ test or Fisher's exact test.

The major endpoint of the analysis was overall survival (OS) calculated from the date of diagnosis until the date of mortality or final follow-up. Progress-free survival (PFS) was defined as survival from the date of diagnosis until the date of i) progression of disease, ii) relapse, iii) mortality from any cause or iv) final follow-up.

A univariate analysis was performed using the Kaplan-Meier method to assess 5-year OS and 5-year PFS. Statistical differences between survival curves were evaluated by log-rank test. Multivariate Cox proportional hazards modeling was conducted using the enter selection technique. In all tests, $\mathrm{P}<0.05$ was used to indicate a significant difference. Hazard ratios (HRs) and their $95 \%$ confidence intervals (CIs) were estimated to assess the magnitude of risk.

\section{Results}

Patients and treatment characteristics. A total of 82 patients with a histologically confirmed diagnosis of PMLBCL who were who were treated in the affiliated hospitals of Central South University between January 2000 and January 2013 were identified. Among these, 19 patients were excluded, as they did not have detailed treatment or follow-up information and were referred only for a second opinion. A total of 63 patients were therefore included in the final analysis. The clinical characteristics and a comparison between the patients with RT and without RT are summarized in Table I. The cohort consisted of 36 males and 27 females. The median age at diagnosis was 28 years (range, 12-78 years). According to the Ann Arbor staging system, 36 patients were in stages I-II $(57.14 \%)$ and 27 patients were in stages III-IV (42.86\%). Bulky disease
A

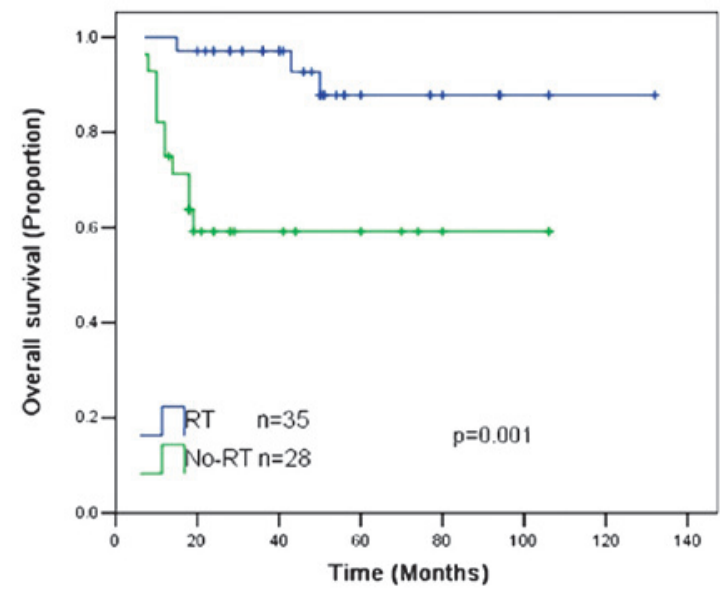

B

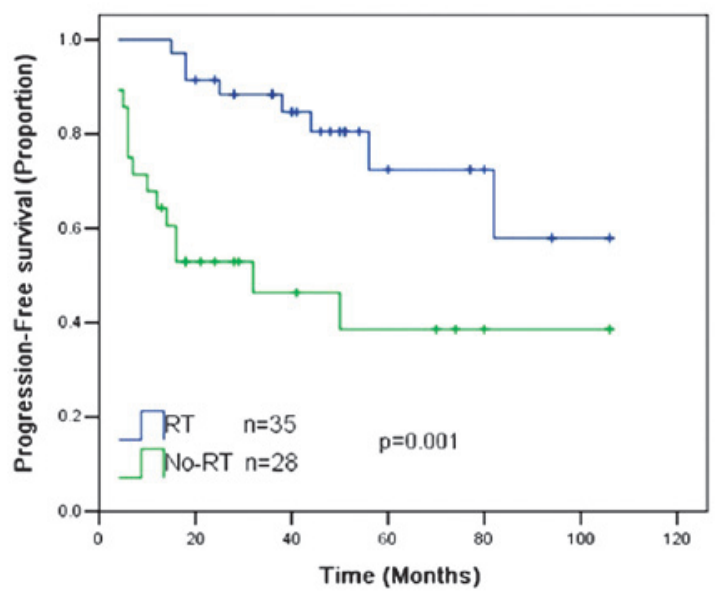

Figure 1. (A) Overall survival and (B) progression-free survival of all patients treated with and without radiotherapy (RT).

was present in 28 patients $(44.4 \%)$. The median follow-up time was 49 months (range, 7-132 months).

All patients received 6-8 cycles of $\mathrm{CHOP}$ or a CHOP-like regimen, with 35 patients $(55.6 \%)$ receiving $\mathrm{RCHOP}$. Post-chemotherapy imaging consisted of PET/CT in $60.3 \%$ of patients and CT in $39.7 \%$. A CR was achieved in 38 patients (60.3\%), PR/SD in 18 (28.6\%) and PD in 7 (11.1\%).

A total of 35 patients who achieved CR or PR following chemotherapy received IFRT to the mediastinum or mediastinum and supraclavicular area. The dosage of IFRT was 40-45 Gy with $6 \mathrm{MV}$ X-rays. IFRT was delivered to 29 out of $36(80.6 \%)$ patients with stage I-II disease and 6 out of $27(22.2 \%)$ patients with stage III-IV disease. Comparisons between the characteristics of patients who received IFRT and those who did not showed that the patients with bulky disease and stage I-II disease received IFRT more frequently (Table I).

Prognostic analysis. The 5-year OS and PFS rates for all patients were 74 and 59\%, respectively. RT was associated with significantly improved 5-year OS (87 vs. 58\%; P=0.001) and 5-year PFS (75 vs. 39\%; $\mathrm{P}=0.001$ ) rates compared with the patients without RT (Fig. 1).

The role of RT in the setting of R-CHOP chemotherapy remains unclear. An analysis was performed on 35 patients who received 6-8 cycles of R-CHOP separately, and it was found that RT could not improve the 5-year OS (88 vs. 92\%; 
Table I. Patient clinical characteristics and a comparison between patients with RT and without RT.

\begin{tabular}{|c|c|c|c|c|}
\hline Variable & Total & RT & No RT & P-value \\
\hline Total, $\mathrm{n}$ & $63(100.00)$ & $35(55.6)$ & $28(44.4)$ & NA \\
\hline Gender, n (\%) & & & & 0.620 \\
\hline Male & $36(57.1)$ & $21(60.0)$ & $15(53.6)$ & \\
\hline Female & $27(42.9)$ & $14(40.0)$ & $13(46.4)$ & \\
\hline Age, n (\%) & & & & 0.800 \\
\hline$\leq 30$ years & $34(54.0)$ & $18(51.4)$ & $16(57.1)$ & \\
\hline$>30$ years & $29(46.0)$ & $17(48.6)$ & $12(42.9)$ & \\
\hline Median age (range), years & $28(12-78)$ & $28(15-67)$ & $29(12-78)$ & 0.708 \\
\hline AA stage, n (\%) & & & & $0.000^{\mathrm{a}}$ \\
\hline I-II & $36(57.1)$ & $29(82.9)$ & $7(25.0)$ & \\
\hline III-IV & $27(42.9)$ & $6(17.1)$ & $21(75.0)$ & \\
\hline Bulky disease, n (\%) & & & & $0.002^{\mathrm{a}}$ \\
\hline No & $35(55.6)$ & $13(37.1)$ & $22(78.6)$ & \\
\hline Yes & $28(44.4)$ & $22(62.9)$ & $6(21.4)$ & \\
\hline Treated with rituximab, n (\%) & & & & 0.213 \\
\hline No & $28(44.4)$ & $13(37.1)$ & $15(53.6)$ & \\
\hline Yes & $35(55.6)$ & $22(62.9)$ & $13(46.4)$ & \\
\hline LDH, n (\%) & & & & 0.136 \\
\hline$\leq \mathrm{UNL}$ & $36(57.1)$ & $23(65.7)$ & $13(42.4)$ & \\
\hline$>\mathrm{UNL}$ & $27(42.9)$ & $12(34.3)$ & 15 (57.6) & \\
\hline IPI, n (\%) & & & & 0.195 \\
\hline $0-1$ & $38(60.3)$ & $24(68.6)$ & $14(50.0)$ & \\
\hline$\geq 2$ & 25 (39.7) & $11(31.4)$ & $14(50.0)$ & \\
\hline
\end{tabular}

${ }^{\text {aP }}<0.05$. RT, radiotherapy; AA stage, Ann Arbor stage; LDH, lactate dehydrogenase; UNL, upper normal limit; IPI, International Prognostic Index.
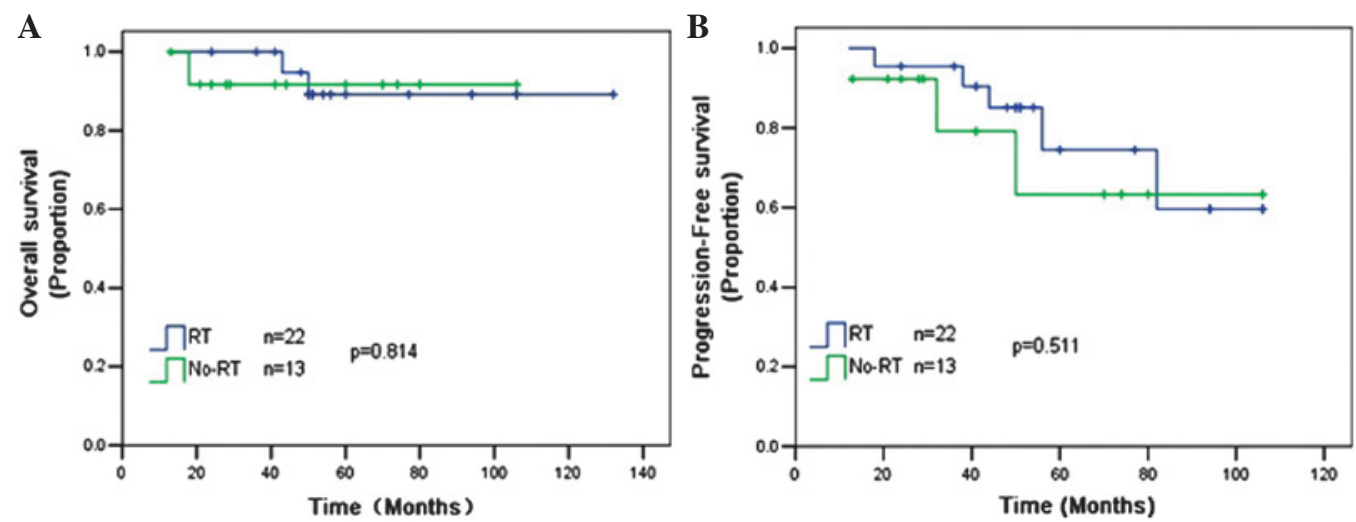

Figure 2. (A) Overall survival and (B) progression-free survival of patients treated with rituximab plus chemotherapy, with and without radiotherapy (RT).

$\mathrm{P}=0.814)$ and 5-year PFS (78 vs. 65\%; $\mathrm{P}=0.511)$ rates compared with patients without RT (Fig. 2).

An analysis was further performed on 56 patients who achieved CR, PR or SD after chemotherapy. RT was associated with a significantly improved 5-year OS rate (87 vs. 69\%; $\mathrm{P}=0.022)$ and exhibited a trend towards an improved 5-year PFS rate $(75$ vs. $52 \% ; \mathrm{P}=0.075)$ compared with patients without RT (Fig. 3).
On univariate analysis of all patients, five factors, namely stage, the addition of rituximab, treatment with RT, IPI score and response to chemotherapy, were found to significantly affect the OS and PFS rates (Table II).

On multivariate analysis, RT (HR, 0.157; $\mathrm{P}=0.018)$ and the addition of rituximab to CHOP chemotherapy (HR, 0.156; $\mathrm{P}=0.009)$ were predictive of an increased OS rate. Similarly, RT (HR, 0.111; $\mathrm{P}=0.001)$ and the addition of rituximab to 
Table II. Univariate analysis of OS and PFS rates for all patients.

\begin{tabular}{|c|c|c|c|c|}
\hline Variable & 5 -year OS rate $(\%)$ & P-value & 5-year PFS rate $(\%)$ & P-value \\
\hline Total & 74 & & 59 & \\
\hline Gender & & 0.852 & & 0.934 \\
\hline Male & 74 & & 57 & \\
\hline Female & 74 & & 63 & \\
\hline Age, years & & 0.471 & & 0.447 \\
\hline$\leq 30$ & 81 & & 51 & \\
\hline$>30$ & 70 & & 66 & \\
\hline AA stage & & $0.001^{\mathrm{a}}$ & & $0.012^{\mathrm{a}}$ \\
\hline I-II & 88 & & 69 & \\
\hline III-IV & 57 & & 50 & \\
\hline Radiotherapy & & $0.001^{\mathrm{a}}$ & & $0.001^{\mathrm{a}}$ \\
\hline No & 58 & & 39 & \\
\hline Yes & 87 & & 75 & \\
\hline Treated with rituximab & & $0.001^{\mathrm{a}}$ & & $0.000^{\mathrm{a}}$ \\
\hline No & 58 & & 44 & $0.000^{\mathrm{a}}$ \\
\hline Yes & 88 & & 74 & \\
\hline Response & & $0.000^{\mathrm{a}}$ & & \\
\hline $\mathrm{CR}$ & 89 & & 75 & \\
\hline $\mathrm{PR}+\mathrm{SD}$ & 63 & & 38 & \\
\hline $\mathrm{PD}$ & 21 & & 0 & \\
\hline Bulky disease & & 0.960 & & 0.747 \\
\hline No & 72 & & 58 & \\
\hline Yes & 76 & & 61 & \\
\hline LDH & & 0.743 & & 0.225 \\
\hline$\leq \mathrm{UNL}$ & 74 & & 61 & \\
\hline$>\mathrm{UNL}$ & 76 & & 61 & \\
\hline IPI & & $0.017^{\mathrm{a}}$ & & $0.023^{\mathrm{a}}$ \\
\hline $0-1$ & 82 & & 65 & \\
\hline$\geq 2$ & 63 & & 52 & \\
\hline
\end{tabular}

${ }^{a} \mathrm{P}<0.05$. OS, overall survival; PFS, progression-free survival; AA stage, Ann Arbor stage; LDH, lactate dehydrogenase; UNL, upper normal limit; IPI, International Prognostic Index; CR, complete response; PR, partial response; SD, stable disease; PD, progressive disease.

CHOP chemotherapy $(\mathrm{HR}, 0.231 ; \mathrm{P}=0.002)$ were predicative of an increased PFS rate. Furthermore, there was a trend towards a decreased PFS rate with bulky disease (HR, 2.994; $\mathrm{P}=0.058)$, however, this was not statistically significant (Table III).

\section{Discussion}

The role of RT in PMLBCL is always controversial. In the pre-rituximab era, numerous studies have evaluated the role of RT. Data from a study on 138 PMLBCL patients who were treated in 13 Italian institutions showed that IFRT plus chemotherapy improved the outcome compared with chemotherapy alone $(\mathrm{P}=0.04)$, while consolidation IF-RT to the mediastinum further improved the outcome of $\mathrm{CR}$ patients (8). A retrospective study on 53 PMLBCL patients treated with MACOP-B (methotrexate, doxorubicin, cyclophosphamide, vincristine, prednisone, bleomycin)/VACOP-B (etoposide, doxorubicin, cyclophosphamide, vincristine, prednisone, bleomycin) plus
RT from Padova, Italy, showed that the 5-year disease-free survival and OS rates were 93.42 and $86.6 \%$, respectively. A total of $37.7 \%$ of the patients achieved a CR and $56.6 \%$ of the patients achieved a PR after IFRT plus chemotherapy, while $92 \%$ of the patients who had already obtained a PR improved to a CR following radiotherapy (20). Another retrospective study conducted by a group from Rome, Italy, included 85 patients with PMLBCL, all of whom received third-generation regimen MACOP-B plus IFRT. Following a median follow-up time of 81 months, progression or relapse was observed in 15 out of 84 patients (17.9\%). The 5-year OS and PFS rates were 87 and $81 \%$, respectively. This study showed that MACOP-B and IFRT induced high response and lymphoma-free survival rates (10). In the present study, RT was associated with significantly improved PFS and OS rates compared with patients without RT, and furthermore, the analysis performed on patients who achieved more than PD following chemotherapy showed that RT was associated with a significantly improved 5-year OS 
Table III. Multivariate analysis for clinical outcomes.

\begin{tabular}{llll}
\hline & \multicolumn{3}{c}{ Multivariate analysis } \\
\cline { 2 - 4 } $\begin{array}{l}\text { Factor } \\
\text { P-value }\end{array}$ & HR & $95 \%$ C I \\
\hline OS & & & \\
$\quad$ RT, yes & 0.157 & $0.034-0.731$ & $0.018^{\mathrm{a}}$ \\
Rituximab, yes & 0.156 & $0.039-0.622$ & $0.009^{\mathrm{a}}$ \\
Bulky, yes & 1.634 & $0.432-6.177$ & 0.469 \\
AA stage & 2.216 & $0.434-11.319$ & 0.339 \\
IPI & 1.549 & $0.368-6.523$ & 0.551 \\
PFS & & & \\
RT, yes & 0.111 & $0.032-0.384$ & $0.001^{\mathrm{a}}$ \\
Rituximab, yes & 0.231 & $0.092-0.575$ & $0.002^{\mathrm{a}}$ \\
Bulky, yes & 2.994 & $0.963-9.313$ & 0.058 \\
AA stage & 0.718 & $0.221-2.332$ & 0.582 \\
IPI & 2.181 & $0.707-6.728$ & 0.175 \\
\hline
\end{tabular}

${ }^{\mathrm{a}} \mathrm{P}<0.05$. HR, hazard ratio; OS, overall survival; AA stage, Ann Arbor stage; IPI, International Prognostic Index.

A

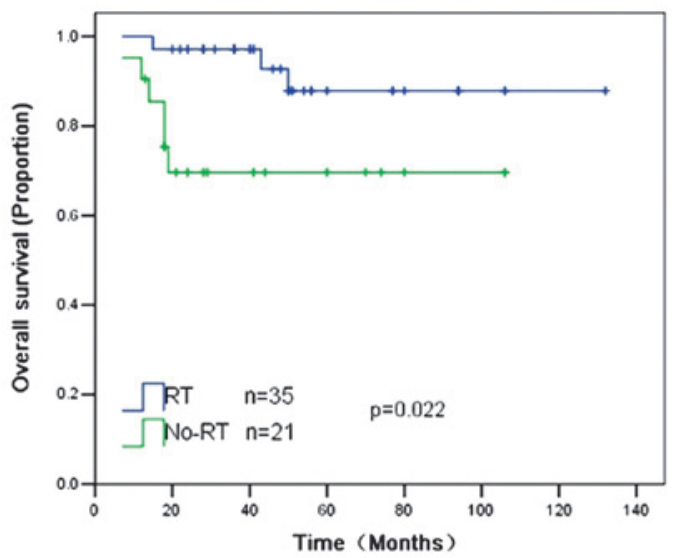

B

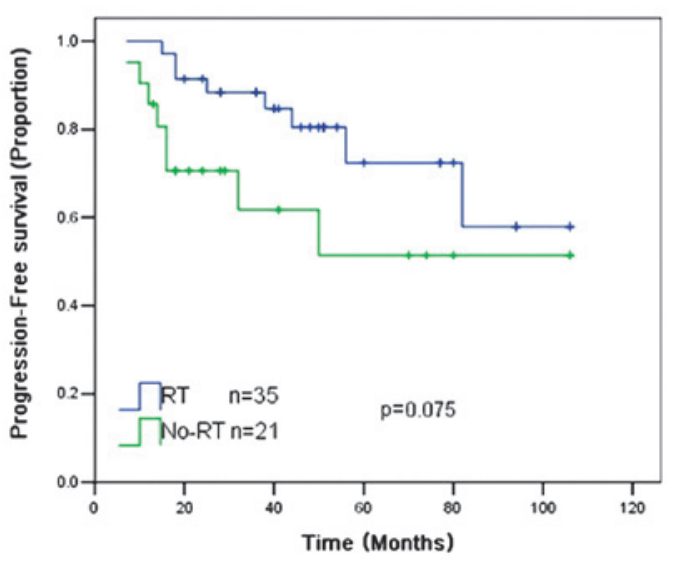

Figure 3. (A) Overall survival and (B) progression-free survival of 56 patients who achieved a complete response, partial response or stable disease following chemotherapy, with and without radiotherapy (RT).

rate and exhibited a trend for an improved 5-year PFS rate, which is similar to the results of the aforementioned studies.
However, there are several studies that do not support this view. A study from the University of British Columbia consisting of 151 patients showed that when comparing the eras prior to and following the routine administration of radiotherapy, there was no significant difference in 5-year PFS (74 vs. $62 \% ; \mathrm{P}=0.09$ ) or OS (78 vs. $69 \% ; \mathrm{P}=0.14$ ) rates $(21)$. Similarly, a study conducted in France suggested that by comparing dose-intensified CHOP and CHOP plus RT, RT may not be necessary in PMLBCL when a CR or a CR, unconfirmed, is achieved with dose-intensified chemotherapy (6).

Indeed, the aforementioned studies were all performed in the era prior to rituximab treatment. Rituximab, as a cluster of differentiation 20 antibody, has revolutionized the treatment of aggressive B-cell lymphomas. The current National Comprehensive Cancer Network 2013 guidelines recommended rituximab as the first-line treatment for PMLBCL. Rituximab combined with chemotherapy has been confirmed to be very effective and safe for PMLBCL in multiple studies $(14,15,22)$, and the superiority of certain intensive regimens over $\mathrm{CHOP}$ for treatment of PMBCL disappeared once rituximab was added (23).

However, several studies suggested that RCHOP was associated with a high rate of primary refractory disease. A study on 37 PMLBCL patients found that $50 \%$ of PMBCL patients showed residual disease on PET scan following rituximab plus chemotherapy (24). A recent retrospective study on 63 PMLBCL patients treated with RCHOP showed that primary induction failure occurred in $13(20.6 \%)$ patients (25).

Furthermore, the question of whether IFRT is still required for PMLBCL in the rituximab era has been raised. In an attempt to clarify the role of RT under the current standard of care, a couple of studies have recently been published. A study from Beijing, China, consisting of 79 patients with PMLBCL indicated that RT plus RCHOP chemotherapy was associated with excellent survival and local control rates. The 5-year OS, PFS and local control rates for early-stage patients were 73.6, 69.9 and $92.6 \%$ for chemotherapy and RT, and $50.8 \%(\mathrm{P}=0.076), 36.9 \%(\mathrm{P}=0.008)$ and $56.4 \%(\mathrm{P}<0.001)$ for chemotherapy alone, respectively (5). However, another study conducted by a group from Greece suggested that the addition of RT to RCHOP chemotherapy did not improve the 5-year PFS (92 vs. 93\%; P>0.2) and 5-year OS (96 vs. 100\%; P>0.2) rates compared with $\mathrm{RCHOP}$ alone (15). The National Cancer Institute group has presented encouraging data with regard to 51 PMLBCL patients who were treated with dose-adjusted etoposide, doxorubicin, cyclophosphamide, vincristine, prednisone and rituximab (DA-EPOCH-R) chemotherapy, without the routine use of RT. During the median 5-year follow-up, the event-free survival and OS rates were 93 and $97 \%$, respectively. A total of $96 \%$ patients achieved a CR (26). The result indicated that DA-EPOCH-R had a high cure rate and removed the requirement for radiotherapy in patients with PMLBCL.

Although the present findings indicated that RT was associated with improved survival for all the patients, in the subgroup analysis of 35 patients who received RCHOP, it was shown that RT could not improve the 5-year OS (88 vs. $92 \%$; $\mathrm{P}=0.814)$ and 5-year PFS (78 vs. 65\%; $\mathrm{P}=0.511)$ rates compared with RCHOP alone. However, these results were limited, as 
the study was retrospective and had an imbalanced number of patients who received RT plus chemotherapy vs. chemotherapy alone.

The present study cannot adequately address whether dose RT can be safely omitted in the rituximab era in selected patients, as the published experience of RT combined with RCHOP (or rituximab plus another chemotherapy regimen) in PMLBCL patients remains limited and is mainly derived from small patient series. The substitution of rituximab for RT requires further investigation.

In summary, the present study demonstrated that RT plus chemotherapy could confer a survival benefit for all patients with PMLBCL, but RT did not confer a survival benefit for patients who were treated with rituximab. It could be considered an option for PMLBCL patients. A number of unanswered questions remain with regard to the management of PMLBCL. The role of RT in the era of targeted therapy should be evaluated in future randomized clinical trials.

\section{References}

1. Harris NL, Jaffe ES, Stein H, Banks PM, Chan JK, Cleary ML, Delsol G, De Wolf-Peeters C, Falini B, Gatter KC, et al: A revised European-American classification of lymphoid neoplasms: A proposal from the International Lymphoma Study Group. Blood 84: 1361-1392, 1994.

2. Steven H: Swerdlow IAfRoC, World Health Organization: WHO classification of tumours of haematopoietic and lymphoid tissues. International Agency for Research on Cancer 2008.

3. No authors listed: A clinical evaluation of the international lymphoma study group classification of non-Hodgkin's lymphoma. The non-hodgkin's lymphoma classification project. Blood 89: 3909-3918, 1997.

4. Zhu YJ, Huang JJ, Xia Y, Zhao W, Jiang WQ, Lin TY, Huang HQ and Li ZM: Primary mediastinal large B-cell lymphoma (PMLBCL) in Chinese patients: Clinical characteristics and prognostic factors. Int J Hematol 94: 178-184, 2011.

5. Xu LM, Fang H, Wang WH, et al: Prognostic significance of rituximab and radiotherapy for patients with primary mediastinal large B-cell lymphoma receiving doxorubicin-containing chemotherapy. Leuk Lymphoma 54: 1684-1690, 2013.

6. Massoud M, Koscielny S, Lapusan S, Bosq J and Ribrag V: Primary mediastinal large B-cell lymphomas treated with dose-intensified CHOP alone or CHOP combined with radiotherapy. Leuk Lymphoma 49: 1510-1515, 2008.

7. Hamlin PA, Portlock CS, Straus DJ, et al: Primary mediastinal large B-cell lymphoma: Optimal therapy and prognostic factor analysis in 141 consecutive patients treated at Memorial Sloan Kettering from 1980 to 1999. Br J Haematol 130: 691-699, 2005

8. Todeschini G, Secchi S, Morra E, et al: Primary mediastinal large B-cell lymphoma (PMLBCL): Long-term results from a retrospective multicentre Italian experience in 138 patients treated with CHOP or MACOP-B/VACOP-B. Br J Cancer 90 : 372-376, 2004.

9. Zinzani PL, Martelli M, Bertini M, et al: Induction chemotherapy strategies for primary mediastinal large B-cell lymphoma with sclerosis: A retrospective multinational study on 426 previously untreated patients. Haematologica 87: 1258-1264, 2002

10. De Sanctis V, Finolezzi E, Osti MF, et al: MACOP-B and involved-field radiotherapy is an effective and safe therapy for primary mediastinal large B cell lymphoma. Int J Radiat Oncol Biol Phys 72: 1154-1160, 2008.

11. Sehn LH, Donaldson J, Chhanabhai M, et al: Introduction of combined CHOP plus rituximab therapy dramatically improved outcome of diffuse large B-cell lymphoma in British Columbia. J Clin Oncol 23: 5027-5033, 2005.

12. Pfreundschuh M, Trümper L, Osterborg A, et al: CHOP-like chemotherapy plus rituximab vs. CHOP-like chemotherapy alone in young patients with good-prognosis diffuse large-B-cell lymphoma: A randomised controlled trial by the MabThera International Trial (MInT) Group. Lancet Oncol 7: 379-391, 2006.
13. Johnson PWM and Davies AJ: Primary mediastinal B-cell lymphoma. Hematology/the Education Program of the American Society of Hematology. Hematology Am Soc Hematol Educ Program 2008: 349-358, 2008.

14. Rieger M, Osterborg A, Pettengell R, White D, Gill D, Walewski J, Kuhnt E, Loeffler M, Pfreundschuh M and Ho AD; Mab Thera International Trial (MInT) Group: Primary mediastinal B-cell lymphoma treated with CHOP-like chemotherapy with or without rituximab: Results of the Mabthera International Trial Group study. Ann Oncol 22: 664-670, 2011.

15. Vassilakopoulos TP, Pangalis GA, Katsigiannis A, Papageorgiou SG, Constantinou N, Terpos E, Zorbala A, Vrakidou E, Repoussis P, Poziopoulos C, et al: Rituximab, cyclophosphamide, doxorubicin, vincristine and prednisone with or without radiotherapy in primary mediastinal large B-cell lymphoma: The emerging standard of care. Oncologist 17: 239-249, 2012.

16. Carbone PP, Kaplan HS, Musshoff K, Smithers DW and Tubiana M: Report of the committee on hodgkin's disease staging classification. Cancer Res 31: 1860-1861, 1971.

17. No authors listed: A predictive model for aggressive non-hodgkin's lymphoma. The international non-hodgkin's lymphoma prognostic factors project. N Engl J Med 329: 987-994, 1993.

18. Juweid ME, Wiseman GA, Vose JM, Ritchie JM, Menda Y, Wooldridge JE, Mottaghy FM, Rohren EM, Blumstein NM, Stolpen A, et al: Response assessment of aggressive non-Hodgkin's lymphoma by integrated International Workshop Criteria and fluorine-18-fluorodeoxyglucose positron emission tomography. J Clin Oncol 23: 4652-4661, 2005.

19. Cheson BD, Pfistner B, Juweid ME, Gascoyne RD, Specht L, Horning SJ, Coiffier B, Fisher RI, Hagenbeek A, Zucca E, et al: Revised response criteria for malignant lymphoma. J Clin Oncol 25: 579-586, 2007.

20. Mazzarotto R, Boso C, Vianello F, Aversa MS, Chiarion-Sileni V, Trentin L, Zambello R, Muzzio PC, Fiore D and Sotti G: Primary mediastinal large B-cell lymphoma: results of intensive chemotherapy regimens (MACOP-B/VACOP-B) plus involved field radiotherapy on 53 patients. A single institution experience. Int J Radiat Oncol Biol Phys 68: 823-829, 2007.

21. Savage KJ, Al-Rajhi N, Voss N, Paltiel C, Klasa R, Gascoyne RD and Connors JM: Favorable outcome of primary mediastinal large B-cell lymphoma in a single institution: The British Columbia experience. Ann Oncol 17: 123-130, 2006.

22. Zinzani PL, Stefoni V, Finolezzi E, Brusamolino E, Cabras MG, Chiappella A, Salvi F, Rossi A, Broccoli A and Martelli M: Rituximab combined with MACOP-B or VACOP-B and radiation therapy in primary mediastinal large B-cell lymphoma: A retrospective study. Clin Lymphoma Myeloma 9: 381-385, 2009.

23. Avigdor A, Sirotkin T, Kedmi M, Ribakovsy E, Berkowicz M, Davidovitz Y, Kneller A, Merkel D, Volchek Y, Davidson T, et al: The impact of R-VACOP-B and interim FDG-PET/CT on outcome in primary mediastinal large B cell lymphoma. Ann Hematol 93: 1297-1304, 2014.

24. Filippi AR, Piva C, Giunta F, Bellò M, Chiappella A, Caracciolo D, Zotta M, Douroukas A, Ragona R, Vitolo U, et al: Radiation therapy in primary mediastinal B-cell lymphoma with positron emission tomography positivity after rituximab chemotherapy. Int J Radiat Oncol Biol Phys 87: 311-316, 2013.

25. Soumerai JD, Hellmann MD, Feng Y, Sohani AR, Toomey CE, Barnes JA, Takvorian RW, Neuberg D, Hochberg EP and Abramson JS: Treatment of primary mediastinal B-cell lymphoma with rituximab, cyclophosphamide, doxorubicin, vincristine and prednisone is associated with a high rate of primary refractory disease. Leuk Lymphoma 55: 538-543, 2014.

26. Dunleavy K, Pittaluga S, Maeda LS, Advani R, Chen CC, Hessler J, Steinberg SM, Grant C, Wright G, Varma G, et al: Dose-adjusted EPOCH-rituximab therapy in primary mediastinal B-cell lymphoma. N Engl J Med 368: 1408-1416, 2013. 